Journal of the Bangladesh Association of Young Researchers (JBAYR), Volume 1 Number 1, January 2011, Page 31-48

ISSN 1991-0746 (Print), ISSN 2220-119X (Online), DOI: 10.3329/jbayr.v1i1.6837

\section{THE NATURE OF TEACHER FEEDBACK IN SECOND LANGUAGE (L2) WRITING CLASSROOMS: A STUDY ON SOME PRIVATE UNIVERSITIES IN BANGLADESH}

Md. Ziaul Karim and Taslima Irine Ivy

Department of English, Presidency University

E-mail: ziaul007_karim@yahoo.com, taslimairine@yahoo.com

\section{ABSTRACT}

The core task of second language (L2) writing teachers is to help students become efficient writers by building up student confidence and providing effective strategies to improve student writing. Teacher feedback given during various stages of process writing can play a vital role in this respect. This paper tried to find out the prevalent forms and nature of teacher feedback in L2 writing classrooms of some private Universities (e.g. dominant forms of feedback, the effect of feedback, amount of importance attached to feedback sessions, attitude towards students in the process \& teacher training on feedback). At the same time it also looked into the effect of feedback on students (whether students view feedback as important, what kinds of feedback students prefer, what they expect from the teacher $\&$ whether they feel positive about receiving feedback). Based on these findings some suggestions based on recent literature were added to help improve feedback methods according to one's own context.

KEYWORDS: Feedback to L2 writing, Feedback in ESL/EFL classroom, Feedback nature and type in Bangladesh.

\section{INTRODUCTION}

The field of teacher feedback has been considered to be a complex but important issue in L2 writing. For the past two decades or so, a number of teachers and researchers have explored the nature and effects of teacher feedback in second language writing classrooms (e.g., Conrad \& Goldstein, 1999; Polio, Fleck \& Leder, 1998; Zamel, 1985 as cited in Ryoo,2004, p. 116). As Ferri notes, "many important questions about teacher feedback to tertiary level L2 writing have not been adequately explored and research findings in this area has been somewhat inconclusive and contradictory" (cited in Ryoo, 2004, p. 120). Despite the increasing interest in $\mathrm{L} 2$ writing, the scenario for teacher feedback in Bangladesh is as Ferri's quote "not adequately explored." However, teachers here are aware of the fact that effective feedback instantly builds confidence in students and substantially increases their interest and effort to become better writers. On the other hand if negative feedback is not conveyed properly by the teachers that is, if criticism is not constructive it may make a student lose interest in writing once and for all. Therefore, we must take some time to reflect on our feedback techniques and think about it's effect on student writing; and that precisely was the prime interest of this study.

\section{LITERATURE REVIEW}

Feedback has been defined primarily as any response (even facial expression) from the teacher reader to the student writer's writing at any stage of the writing process. According to Keh (1996), "Feedback is a fundamental element of the process approach to writing. It can be defined as input from a reader to a writer with the effect of providing information to the writer for revision" (p.295).

Feedback in its various forms has been present from the beginning of teaching writing. Up until the early $20^{\text {th }}$ century writing was viewed as a product. So, the most common role for the teacher was to be a judge, a critical evaluator of the finished product (indicating mistakes and correcting errors). In Sokolik's (2003) words it was not until the 1960's that "writing instruction began to include the entire process of writinginvention, drafting, feedback and revision- and not just the product" (p.89). As research started to look into the various effects and forms of feedback, more and more importance became attached to the concept and turned feedback into an inevitable part of the whole writing process. The dominant forms of feedback found to be practiced by teachers can be summarized as follows: 
Table 1 Feedback types with brief descriptions

\begin{tabular}{|c|c|}
\hline Feedback Type & Brief description \\
\hline $\begin{array}{l}\text { 1. Error Correction (Alwright, } \\
\text { 1975; Norish 1983; Hendrickson } \\
\text { 1984; Chaudron } 1988 \text { cited in } \\
\text { Khan. R, 2003) }\end{array}$ & $\begin{array}{l}\text { The oldest and widely reported } \\
\text { form. Involves indicating and } \\
\text { correcting errors in the text. Error } \\
\text { correction may be coded or } \\
\text { uncoded. }\end{array}$ \\
\hline $\begin{array}{l}\text { 2. Peer Correction (Lynch 1988, } \\
\text { Robinson, 1991; Arndt, 1993; } \\
\text { Keh } 1996 \text { cited in Khan.R, 2003) }\end{array}$ & $\begin{array}{l}\text { Students' critiquing and providing } \\
\text { one another's writing }\end{array}$ \\
\hline $\begin{array}{l}\text { 3. Conferences (Freedman and } \\
\text { Sperling, 1985; Hedge, 1988; } \\
\text { Keh 1996; Arndt } 1993 \text { cited in } \\
\text { Khan. R, 2003) }\end{array}$ & $\begin{array}{l}\text { Face to face meeting between } \\
\text { teachers and students in which } \\
\text { "the teacher acts as a live } \\
\text { audience and helps the writer } \\
\text { sort through problems and assist } \\
\text { the student in decision making. }\end{array}$ \\
\hline $\begin{array}{l}\text { 4. Written comments (Rairnes } \\
\text { 1988; Fathmen and Whalley, } \\
\text { 1990; Leki } 1990 \text { cited in Khan. R, } \\
\text { 2003) }\end{array}$ & $\begin{array}{l}\text { The teacher writes comments on } \\
\text { different aspects of the written } \\
\text { tasks in the margins, spaces } \\
\text { between paragraphs or at the } \\
\text { end }\end{array}$ \\
\hline $\begin{array}{l}\text { 5. Reformulation (Cohen 1982; } \\
\text { Alwright 1988; Hedge } 1988 \\
\text { cited in Khan. R, 2003) }\end{array}$ & $\begin{array}{l}\text { Rewriting student text while } \\
\text { keeping the original ideas intact. }\end{array}$ \\
\hline $\begin{array}{l}\text { 6. Text approximation (Holes, } \\
1984 \text { cited in Khan. } R, 2003 \text { ) }\end{array}$ & $\begin{array}{l}\text { Students use multiple drafts and } \\
\text { revise a number of times to } \\
\text { approximate an English text of a } \\
\text { similar type. }\end{array}$ \\
\hline $\begin{array}{l}\text { 7. Taped Commentary (Hyland } \\
\text { 1990; Schriver 1991; Boswood } \\
\text { and Dwyer, } 1995 \text { cited in Khan. } \\
\text { R, 2003) }\end{array}$ & $\begin{array}{l}\text { Recording teacher's remarks on } \\
\text { tape. Teachers also write } \\
\text { numbers on the student's written } \\
\text { text along with the comments } \\
\text { they make so it is easy for the } \\
\text { student to locate and identify the } \\
\text { problem area. }\end{array}$ \\
\hline 8. Grades/Number & Assigning marks or grades \\
\hline
\end{tabular}

Adapted from Khan, R. (2003; pp. 3-12)
This study looked into which of these types of feedback were being practiced in the Universities and how effectively.

From the point of purpose (whether we want to mould or evaluate) feedback has been said to be of two types:

1. According to Ur (2003) "Most of the feedback we give our learners is ongoing correction and assessment, directed at specific bits of learner-produced language with the aim of bringing about improvement; the type of evaluation involved here is sometimes called 'formative', since it's main purpose is to 'form'; to enhance, not conclude, a process" (p.244).

2. Distinct from this is the evaluation in Ur's (2003) words is the feedback "usually termed 'summative', where the teacher evaluates an overall aspect of the learner's knowledge in order to summarize the situation: how proficient he or she is at a certain point in time" (p.244).

Depending on the explicitness feedback may be direct (errors are fully corrected or partially rewritten) or indirect (an error is indicated not corrected). However, we used 'feedback' as an umbrella term including both the summative/formative and direct/indirect mode.

Ur (2003) also distinguished two main components of feedback: assessment and correction. "In assessment the learner is simply informed how well or badly he or she has performed............In correction, some specific information is provided on aspects of the learner's performance: through explanation or provision of better or other alternatives or through elicitation of these from the learner “(p. 242).

Approaches to giving feedback vary widely. The differing views on feedback (comprising both components assessment and correction) can be summarized as follows: 
Table 2: The Provision of Assessment: Different opinions

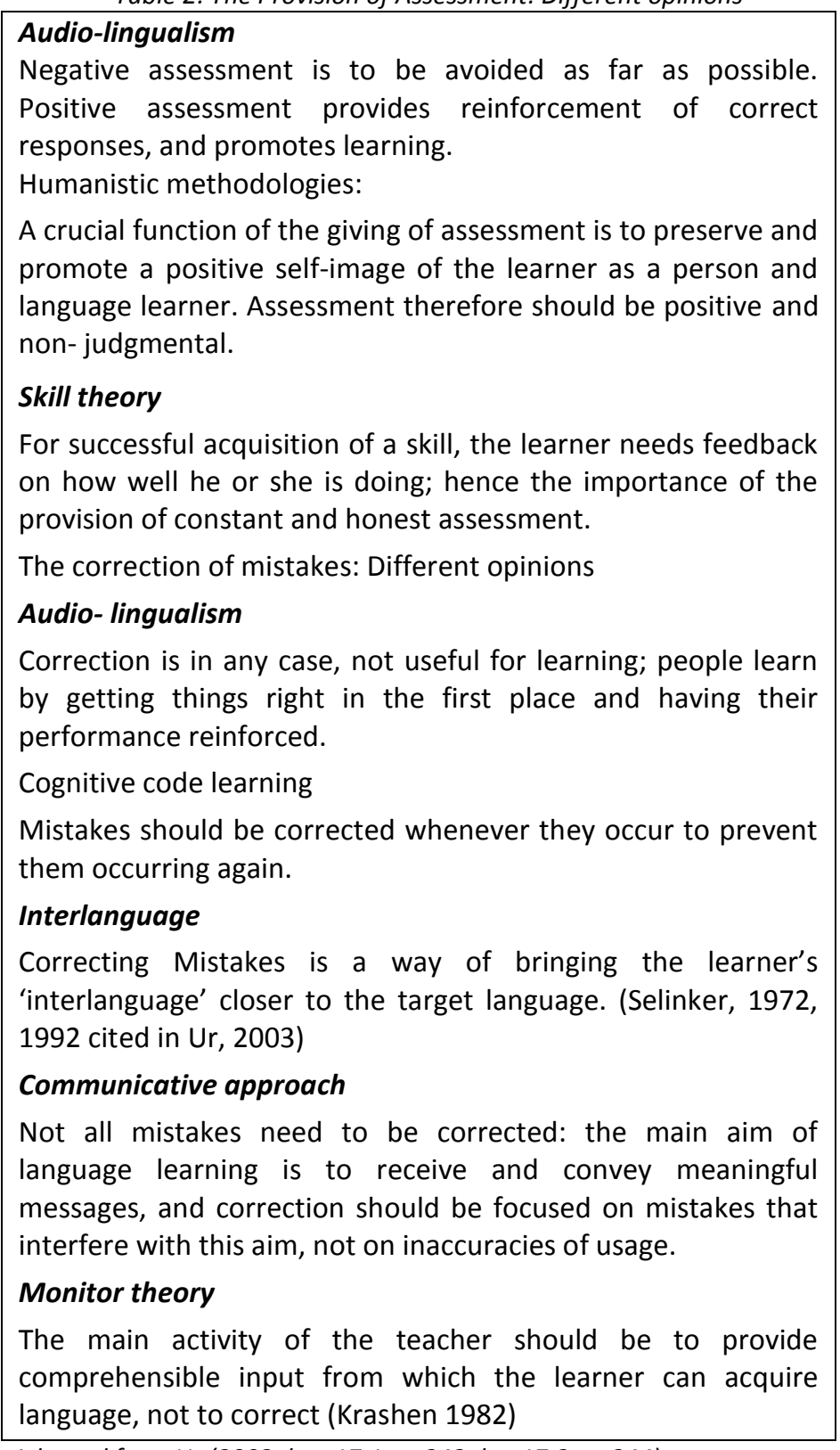

Adapted from $\operatorname{Ur}(2003$, box 17.1, p. 243; box17.2, p. 244)
This study looked into what approaches teachers and students in Bangladesh have towards feedback e.g. is it deemed necessary, how effective it is and do the participants react to feedback sessions in a positive or negative manner.

There has been an inconclusive debate about which features of a student's writing should receive teacher feedback and which areas should be left alone and can not be improved. Some researchers strived to prove that grammar instruction can not improve language, so teachers should focus on 'higher order concerns' (Keh, 1996) e.g coherence, development of ideas, etc. than 'lower order concerns' (Keh, 1996) e.g. grammar. Krashen (2003) is a strong adherent against grammar instruction as he holds the view that grammar instruction only aids language learning not language acquisition. However, according to Krashen some grammar knowledge may be helpful for advanced learners in editing. Another proponent against grammar correction is Jhon Truscott $(1996,1999)$ who not only opposed grammar correction but held that it was harmful. Ferris (1999, 2004) holds an opposite position to Truscott's 'strong stance.' Ferris has shown that the research base is inadequate in this regard and more research is needed.

Ferris (2003) is also of the opinion that teachers should provide feedback on all aspects of student texts including content, rhetorical structure, grammar and mechanics. During the 80's most instructors were afraid of providing feedback during the early stages of writing and thought it would destroy student confidence. But According to Ferris (2002) "most L2 writers know that errors exist in their writing and want error correction as part of the writing process" (p. 29). Rather, making all corrections on the final product may result in a huge amount of comments and corrections exhausting the teacher as well as discouraging the student. The best approach was seen to provide feedback throughout the process of writing. Ferris (2003) strongly supported the opinion "feedback is effective when it is delivered at intermediate stages of the writing process" (p. 122). As such this study also looked into teacher feedback during different the stages of process writing to see whether the practice in Bangladesh confirmed to dominant literature. 


\section{METHOD}

\section{Participants}

Participants included 18 teachers and 58 Students from five private universities (BRAC University, East West University, Independent University of Bangladesh, Presidency University and Southeast University) in Bangladesh. The teachers were all instructors of $L 2$ writing classes at the undergraduate level. Among teacher respondents 6 were from Presidency University (PU), 4 from East West University, 3 from Southeast University, 3 from Independent University of Bangladesh (IUB) and 3 were from BRAC University. The student questionnaire was given to undergraduate students of private universities who have completed core L2 writing courses. Among them 20 Students were from Presidency University, 12 students from East West University, 10 students from Independent University of Bangladesh (IUB), 10 students from Southeast University and 6 students were from BRAC University.

\section{Materials}

Two separate questionnaires were designed to elicit information about feedback from both the teacher's and student's point of view. The questionnaires included 10 questions based on five aspects of feedback: importance, preferred types, attitude/approach towards feedback, efficacy, during which stage of writing it was given and training on feedback. We used both close-ended (e.g. yes/no) and open-ended (e.g. give two suggestions for improving FB) questions. The participants were also allowed to pick more than one options (for preferred types and stages) where necessary.

\section{Procedure}

The respondents were given the questionnaires to fill out anonymously. The teachers' responses were collected within two working days. The students were given the questionnaires after class sessions and were required to respond on spot.

\section{FINDINGS AND DISCUSSION}

\section{Importance of Feedback}

One of the aims of this study was to find out how important teachers and students held feedback to be. Results indicated that both teachers and students in Bangladesh view feedback as a very important part of process writing.
All teachers (100\%) were found to provide students with feedback on writing. $100 \%$ students affirmed that they do in reality receive feedback on all of their writing materials. $63.79 \%$ students reported of teachers arranging extra sessions for feedback apart from taking the class. This indicated the extra effort teachers were putting into giving feedback to students at the tertiary level. Some of the teacher comments about the importance of feedback were as follows:

- $\quad$ Students need more than a general guideline on how to improve their writing and feedback serves the purpose.

- For motivating the students in a positive way and giving them confidence. It enables Students to find out their own way to use their innate talent and intuitive power.

- $\quad$ Because it provides a transparent idea of what the Students have acquired and helps them to review their mistakes.

- $\quad$ The Students can understand their strength and weakness.

- Interaction grows stronger.

Students too perceived teacher feedback as a very important factor in L2 writing. Some important student comments in this regard were as follows:

- Because teacher's feedback helps me identify my mistakes and clear any doubts.

- It is a great opportunity to reduce my mistakes, develop my knowledge and edit myself.

- $\quad$ Feedback creates better communication between teachers and students.

- It enables to rectify my way of writing and highlights the weaknesses in my writing.

- $\quad$ Feedback works as a motivation for me.

One interesting point was that both teachers and students viewed feedback necessary not only for improving writing but also as a platform for developing interaction and communication. The study thus reconfirmed that feedback in practice should be an inevitable part of writing.

\section{Preferred Types of Feedback}

All teachers chose error correction (100\%) as the most effective form of feedback. Next priority was given to written comments (77.77\%). Peer correction (72.22\%).) and assigning grades/numbers were the third choice. Half of the teachers found conferences and verbal comments to be an 
effective form of feedback (55.55\%), while a little less $(50 \%)$ agreed that multiple drafts and revision was also effective in the class. Teachers were least interested in Taped commentary and pre writing discussions with students. Only $5.55 \%$ felt these techniques should be used in L2 writing classrooms.

The largest part of student respondents felt written comments (74.13\%) and conferences $(60.34 \%)$ to be most helpful. The next student priority was verbal comments (58.62\%). Ranking fourth were Peer feedback and grades together $(41.37 \%$ student priority). Feedback through multiple drafts and revision (Text approximation) were found to be least preferred (25.86\% students). Taped Commentary and Reformulation was not reported to be in use as a feedback method in any of the institutions (0\%).

Table 3: Priority based ranking of feedback types

\begin{tabular}{|l|l|}
\hline \multicolumn{1}{|c|}{ Teacher ranking } & \multicolumn{1}{|c|}{ Student ranking } \\
\hline 1. Error correction & 1. Written comments \\
\hline 2. Written comments & 2. Conference \\
\hline 3. Peer Feedback and Grades & 3. Verbal Comments \\
\hline \begin{tabular}{l} 
4. $\quad \begin{array}{l}\text { Conferences and verbal } \\
\text { comments }\end{array}$ \\
\hline 5
\end{tabular} 4. Multiple drafts and revision & 5. Multiple drafts and revision \\
\hline
\end{tabular}

Although Error correction was preferred by teachers, in practice written comments is the form of feedback that is being used most of the time (74.13\% students reported they receive written comments as feedback).

Despite high student preference (second place) for 'conference', few (31\%) students reported that teachers arrange conferences for them. The scene for verbal comments is quite the same for students and teachers and as such it is being used quite widely $(62.06 \%$ students reported getting verbal comments as feedback.)

An interesting fact worth noting was while most of the teacher respondents (72.22\%) believed peer feedback should be used in the classroom, only a small (34.48\%) percentage of students reported of peer feedback to be used in the class. The reason for this inconsistency may lie in the fact that peer feedback was relatively unknown in our context and the concept has been introduced through theory very recently. As such while teachers may feel this to be a powerful technique in practice they are still sticking to the more familiar approaches.

Again, where most teachers (72.22\%) supported grading to be an effective technique student preference was low (41.37\%).

About half of the teachers felt multiple drafts and revision should be used but no more than $25.86 \%$ students preferred it and only $13.79 \%$ reported of it being used in the classroom.

Pre-writing discussions and taped commentary were the last preference and no student informed of the technique being used in class.

We concluded "error correction" and "written comments" to be the most dominant forms of feedback used in the tertiary level $L 2$ writing classes in Bangladesh whereas students were more inclined to getting feedback in the form of written comments and conference. Teachers have stated some important issues behind their likings:

- Written comments give students inspiration and help a lot to make the next draft.

- Building up a friendly relationship in a classroom gets priority. I try to assure that the Ss can come to me anytime if I am free. Keeping that in mind I provide feedback in different methods.

- We think written feedback is important for students to read when the teacher is not there to help them. Peer correction and conferences make a greater impact on them. Ss can retain more of what they learn during these sessions.

- $\quad$ Error correction, peer correction, written comments and giving grades/numbers are a few methods that are mostly practiced and students are quite familiar with them.

- $\quad$ For the weak students I try to write comments in a way they don't feel bad, rather realize exactly what they need to do. For the good ones I always give encouraging comments and I found that they are always happy with the right feedback.

- We would like to create inventive ideas in students. Ss will have a pre-writing discussion with the teacher. This will generate free thinking ideas in Ss and the structural feedback along with opening up scopes for both contextual and non-contextual writing. 
A few of the reasons behind student preferences were:

- Verbal comments are needed for our understanding and written comments remain with us as a document for our faults that reminds us not to make the same mistakes.

- Written comments help to guess the errors very easily and if I still have the problem then a meeting with the teacher can be effective.

- Grades give our improvement status.

- $\quad$ Through meeting my teacher I can take her ideas about how to improve myself.

\section{Attitude}

Data analysis from student questionnaires showed teachers to be more positive than negative while giving feedback (51.73\%). Just about half of the students $(44.83 \%)$ admitted getting very positive feedback from teachers. More negative than positive attitude was negligible (only 2 responses, $3.45 \%$ ). No student reported of getting a negative attitude from teachers while receiving feedback.

Data analysis from the teacher questionnaire reflected the same pattern. Most $(61.11 \%)$ teachers reported students to take feedback more positively than negatively. $33.33 \%$ students were reported to take it very positively. The survey found $0 \%$ students to have a negative or more negative than positive attitude.

On this basis we inferred tertiary level writing classes in Bangladesh to have a healthy atmosphere during feedback sessions and the reaction of teachers and students usually range on a scale of positive to very positive.

\section{Efficacy}

Most $(62.06 \%)$ students felt teacher feedback was always helping the writing process whereas some $(34.48 \%)$ felt teacher feedback to help 'sometimes'. Barely 3.45\% reported teacher feedback to be not helping at all. On the other hand most of the teachers (61.11\%) felt that their feedback helped students 'sometimes' and only one third (33.33\%) felt that feedback was helping the students 'always'. Only $44.44 \%$ teachers were reported of having attended training or workshops on feedback and as such a lot of teachers $(77.77 \%)$ felt the necessity of attending more training sessions or seminars on this aspect.
In terms of effect of feedback the study concluded, although most students were feeling that teacher feedback was helping them write better the teachers themselves were inclined to develop their effectiveness and were very interested to attend trainings, seminars or workshops on feedback if they were given the opportunity.

\section{Preferred Stages}

The largest part of teachers in the tertiary level L2 writing classes were found to give feedback at the final draft stage or the product stage (7 responses). 4 teachers gave feedback during all stages. Only 1 teacher was found to give feedback during the planning stage and 3 teachers responded to giving feedback only at the drafting stage. The remainder of 3 teachers each gave feedback at the various intermediate stages (Editing and revising; Editing, revising and final draft; Planning, drafting, editing and revising). The following graph displays the amount of teacher feedback during various stages of process writing:

Figure 1: Teacher feedback during different stages of process writing

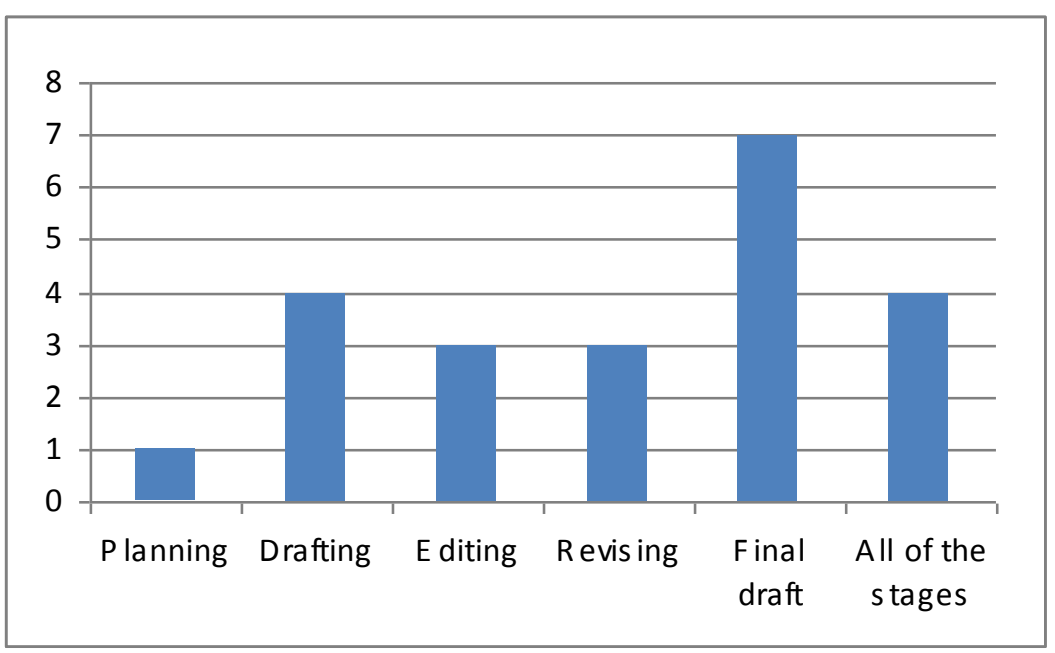

Even though literature suggests giving feedback at the intermediate stages this was not the practice in Bangladeshi tertiary level L2 writing classes. Teachers usually preferred the final draft. 


\section{Training}

Only $44.44 \%$ tertiary level teachers were found to have any formal training on providing feedback. The major trainings were organized by the American Center, BELTA, seminars arranged at different Private Universities etc. Half of the students (51.73\%) thought teachers must receive more training on giving feedback effectively. Most teachers (77.77\%) also felt the necessity as reflected in a participant teacher's comment "giving feedback is a very methodological task. It must be done following an ordered procedure which will channelize student's aptitude in a structurally desired way."

\section{RECOMMENDATIONS}

Based on these findings some specific suggestions for improving feedback in the context of Bangladeshi tertiary level L2 writing classes are as follows:

1. Feedback should be given at the intermediate levels of the writing process. Research by Ferri (2003), Zamel (1985), Leki (1990) has shown that feedback is more effective when it is delivered at the intermediate stages. In the process of subsequent revisions the student can respond to feedback and may more actively attend to the teacher's comments and suggestions (Ferri, 2003; Zamel, 1985). As such, the practice of giving feedback during the final stages should be avoided.

2. High student preference for one to one conference should be taken into consideration. Teachers may think about arranging more conference sessions where it is feasible.

3. As only $41 \%$ students prefer grades and $72 \%$ preferred written comments it would be "a good idea to combine written comments with grades or marks. According to Khan (2003) "this gives substantial amount of feedback to the students" (p. 12).

4. Although most of the teachers (72\%) feel peer feedback should be used less than half of the students (41\%) reported of it being implicated. Teachers therefore, may consider introducing the technique. However, for peer feedback to be effective students must be given a training session demonstrating the procedure prior to starting the task. Students must also be given a complete written set of instructions and an oral explanation of the procedure
5. Extra feedback sessions do help the students to focus more on improving themselves and teachers who have not implemented this yet (36\%) should think about adding sessions to their regular writing classes.

6. The overall atmosphere was reported to be positive. Focus should be on positivity but not false praise. In Khan's (2003) words “Build a helpful spirit and give directions for appropriate and constructive criticism" (p. 12)

Some suggestions from the teacher participants were as follows:

1. The class size should be kept small (preferably 20-25 students) in order for the instructor to give proper feedback. Among general factors, general and specific feedback should be given based on the student- instructor relationship and the objective of the course that is taught. One-size-fits-all feedback should be avoided.

2. Some common mistakes can be discussed in general.

3. Found board work to be a good platform for feedback.

4. Allowing students to ask questions about feedback is necessary. They have many queries like 'why my version is wrong'; instead of explaining the write answer it is better to explain why the teacher's feedback is a better choice.

5. It is not necessary to correct all mistakes and errors. The areas for providing feedback should be selected by the teacher.

6. Feedback should be provided not only on grammar and mechanics but also on content and rhetoric.

\section{CONCLUSION}

In this paper we tried to find out the current status of teacher feedback in Bangladesh at the tertiary level. The encouraging discovery was that feedback is not an abstract idea anymore but teachers are aware of its implications and it is being practiced in the field in a variety of techniques with a positive attitude. On the contrary the most prevalent shortcoming was that teachers were not providing feedback on all stages of process writing. More importance has to be attached to this aspect of giving feedback as it is very important to guide students through the whole process. Taped commentary is not used at all but teachers may consider using it as (Khan, 2003) comments "some shy students may appreciate the privacy and empathy of this medium. It can give students a sense of 
audience for their writing and is considered more useful for responding to global rather than local concerns" (p. 13). Nearly half of the teachers have no formal training on feedback but all of them are interested in improving effectiveness and as such more workshops need to be arranged. Nevertheless, it has to be remembered that there is no one right technique for providing feedback nor there is agreement on which aspect of writing we should be giving feedback on. Each class has its own dynamics and every student is an individual. A combination of techniques may be used or a technique may be refined according to purpose. It is the teacher's responsibility to analyze the needs of the students and also consider the constraints of implementing it; only then will it be possible to work out an effective feedback plan for his or her class.

\section{REFERENCES}

Ferri, D. (1995). Student reactions to teacher response in multiple draft composition classrooms. TESOL Quarterly, 29, pp.33-53.

Ferris, D.R. (1999). The case for grammar correction in L2 writing classes: A response to Truscott (1996). Journal of Second Language Writing, 8, pp. 110.

Ferris, D. R. (2002). Treatment of error in second language writing classes. Ann Arbor, MI: University of Michigan Press.

Ferris, D. R. (2003). Response to student writing: Implications for second language students. Mahwah1, Nj: Lawrence Erlbaum.

Ferris, D. R (2004). The “Grammar Correction” Debate in L2 Writing: Where are we, and where we go from here? (and what do we do in the meantime...?). Journal of Second Language Writing, 13, pp.49-62.

Keh, C. L. (1996). Feedback in the writing process: a model and methods for implementation. In Hedge, T. and Whitney, N. (eds). Power, Practice and Pedagogy (pp. 271-282). Oxford: Oxford University Press.

Khan, R. (2003). Responding to Student Writing in the TESOL Environment: Some Feedback Options. The Dhaka University Studies, June 2002-June 2003, pp.1-16.

Krashen, S. D. (2003). Explorations in Language Acquisition and Use. Portsmouth: $\mathrm{NH}$ : Heinemann.

Leki, I. (1990). Coaching from the margins: issues in written response. In Kroll, B (ed). Second Language Writing: Research Insights for the Classroom (pp. 57-68). Cambridge: Cambridge University Press.
Ryoo, M. (2004). The Effects of Teacher Feedback on EFL Students' Writing in a Korean University Class. THE JOURNAL OF ASIA TEFL, Spring 2004, Vol.1, No.1, pp.115-130.

Sokolik, M. (2003). Writing. In Nunan, D. (ed). Practical English Language Teaching (pp. 87-106). NY: Mcgraw- Hill/ Contemporary.

Truscott, J. (1996). The case against grammar correction in L2 writing classes. Language Learning, 46, pp.327-369.

Truscott, J. (1999). The case for "the case for grammar correction in L2 writing classes": A response to Ferris. Journal of Second Language Writing, 8, pp.111-122.

Ur, Penny. (2003). A Course in English Language Teaching-Practice and theory $\left(10^{\text {th }}\right.$ ed.). UK Cambridge University Press.

Zamel, V. (1985). Responding to student writing. TESOL Quarterly, 19, pp.79-102.

\section{APPENDIX-1}

\section{Findings from the Questionnaires for Teachers}

The following questions have been prepared to conduct a research on feedback to the tertiary level L2 writing in some private universities in Bangladesh. The following information has been gathered from 18 teachers of five different private universities (Presidency, East West, BRAC, IUB, Southeast)

Q1. Do you think feedback is important for the students? Result in percentage (\%) Why do you think so?

Q2. Do you give feedback to your learners?

Result in percentage (\%)

$\begin{array}{cc}\text { Yes } & \text { No } \\ \text { (18 responses) } & \text { (Nil) } \\ 100 \% & 0 \% \\ & \\ \text { Yes } & \text { No } \\ \text { (18 responses) } & \text { (Nil) } \\ 100 \% & 0 \% \\ & \text { Result in } \%\end{array}$

Q3. During which stages of process writing do you usually give

feedback to the students?

Planning (1 response)

Drafting (4 responses)

Editing (3 responses)

Revising (3 responses)

Final draft (7 responses)

All of these stages (4 responses)

Q4. Tick out some of the feedback methods that you feel should be used in the L2 writing classroom

Error correction (18 responses)

Peer correction (13 responses)

Conferences (One to one meeting between teachers and students) (10 responses)
4.55

18.18

13.64

13.64

31.82

18.18

Result in \%

20.93

15.12

11.63 
Verbal comments (10 responses)

11.63

Written comments (14 responses)

16.28

Reformulation (Rewriting the text without distorting original ideas)

8.14

(7 responses)

Text Approximation (multiple drafts and revision) (9 responses)

10.47

Taped commentary (Recording on tape) (1 response)

1.16

Grades/Numbers (13 responses)

Others: Pre-writing discussion with students (1 response)

15.12

1.16

Q5. What is your method of feedback in the L2 writing classroom? Please specify reason/reasons for your choice of the method/ methods.

Q6. How is the student's reaction to feedback?

More negative than positive (Nil)

Very positive (6 responses)

Very negative (Nil)

More positive than negative (11 responses)

No response

Q7. Does your feedback help your student writers edit their texts successfully?

Always (6 responses)

Not at all (Nil)

Sometimes (11 responses)

No response

Q8. Do you have any training or did you attend

any seminar on feedback?

Result in percentage (\%)

If yes, write something about it.

Q9. Do you feel the necessity of training or seminar on feedback?

Result in percentage (\%)

If yes, why?

Q10. Give two suggestions for improving feedback in a writing class.

\section{APPENDIX 2}

\section{Findings from the Questionnaires for Students}

The following questions have been prepared to conduct a research on feedback to the tertiary level L2 writing in Bangladesh. The following information has been gathered from 58 students of four different private universities (Presidency, Eastwest, BRAC, IUB, Southeast)

Q1. Do you think your teacher's feedback is important for

you?

Result in percentage (\%)

Result in \%

0

0

61.11

5.55

Result in \%

33.33

0

5.55

No

(8 responses) (10 responses)

55.55

No

22.22 $\begin{array}{cc}\text { Yes } & \text { No } \\ \text { (58 responses) } & \text { (Nil) }\end{array}$

$100 \% \quad 0 \%$

Q2. Do you get feedback from your teachers?

Yes

No

Result in percentage (\%)

Q3. What kind of feedback do you prefer?

Written comments (43 responses)

Verbal comments (34 responses)

Feedback from your classmates (Peer feedback) (24 responses)

Through a meeting with the teacher (Conference) (35 responses)

Feedback through multiple drafts and revision (Text approximation)

(15 responses)

Grades (24 responses)

Taped commentary (Recording on tape) (0 responses)

Reformulation (Rewriting the text without distorting original ideas) (0 responses)

Please state why you prefer the method.

Q4. What kind of feedback do your teachers give?

Written comments (43 responses)

Verbal comments (36 responses)

Arranging feedback from your classmates (Peer feedback) (20

(58 respons

(Nil)

Through a meeting with the teacher (Conference) (18 responses)

Feedback through multiple drafts and revision (Text approximation)

(08 responses)

Grades (22 responses)

Taped Commentary (0 responses)

Reformulation (Rewriting the text without distorting the original ideas) (0 responses)

Q5. What is the teacher's reaction while giving feedback?

More negative than positive (02 responses)

Very positive (26 responses)

Very negative (Nil)

More positive than negative (30 responses)

Q6. Does your teacher's feedback help you edit your texts successfully? Always (36 responses)

Not at all (02 responses)

Sometimes (20 responses)

Q7. Does your teacher arrange any feedback session apart from taking the class?

Result in percentage (\%)

If yes, write something about it.

Q8. Do you think your teachers should receive training on giving feedback?

Result in percentage (\%)

If yes, why?

Q9. Give two suggestions for improving feedback in a writing class.

Result in \%

24.57

19.43

13.71

20

8.57

13.71

$0 \%$

$0 \%$

Result in \%

29.25

24.49

13.61

12.24

5.44

14.97

Result in \%

3.45

44.83

0

51.73

Result in \%

62.06

3.45

34.48

No

1 responses)

36.21

63.79

Yes

(30 responses)

51.73

No

(28 responses)

48.27

Why do you think so? 